(2) OPEN ACCESS

${ }^{1}$ Health Promotion Department, World Health Organization, Geneva, Switzerland ${ }^{2}$ World Health Organization, New Delhi, India

\section{Correspondence to} Mark Goodchild, World Health Organization, Geneva, Switzerland; goodchildm@who.int

Received 29 June 2020 Revised 22 September 2020 Accepted 1 October 2020

\title{
Revisiting the tax treatment of bidis in India
}

\author{
Mark Goodchild (1) , Vineet Gill Munish, ${ }^{2}$ Praveen Sinha, ${ }^{2}$ Fikru Tesfaye Tullu, ${ }^{2}$ \\ Jeremias Paul ${ }^{1}$
}

\section{ABSTRACT}

Background Bidi use remains an intractable public health problem for India. This is partly due to the informal nature of the bidi supply chain, including tax exemptions for small producers. The aim of this paper is to assess the impact of making all bidis subject to duty and Goods and Services Tax. Although this may require legislative changes and incur some extra administrative costs, the net benefits would include greater oversight of the supply chain as well as increased tax revenues and reduced consumption.

Methods We use a form of gap analysis (the difference between duty paid and total bidi consumption) to estimate the number of tax-exempt bidis. We then use local evidence on the price elasticity of demand for bidis to assess the impact of eliminating these exemptions on the price and consumption of presently tax-exempt bidis. Findings Total bidi consumption is estimated at 400 billion sticks per annum, including 275 billion duty paid sticks and 125 billion duty exempt sticks. Removing the small producer exemptions would increase the price of currently exempt bidis by INR4.6/pack. Total bidi consumption would decrease by $6 \%$ and the number of smokers would decrease by 2.2 million adults. This would bring the rate of bidi smoking down from $7.7 \%$ to $7.5 \%$, while generating INR14.8 billion in tax revenues.

Conclusions Eliminating India's tax exemptions for small bidis producers would make a significant contribution to tobacco control, both directly by reducing the number of smokers and indirectly by plugging a loophole in the supply chain.

\section{INTRODUCTION}

India is the second largest consumer of tobacco products worldwide, with more than 267 million users representing $28.6 \%$ of India's adult population. ${ }^{1}$ A unique feature of India's market is the high use of 'indigenous' tobacco products like chewing tobacco and bidis. There are almost twice as many bidis smokers as there are cigarette smokers-at 72 million bidi smokers vs 38 million cigarette smokers, respectively. ${ }^{1}$

Tobacco use is a major underlying risk factor for cancer and other non-communicable diseases, as well as being linked to communicable diseases like tuberculosis (TB) and now COVID-19. ${ }^{2-4}$ In the case of TB, smoking has been linked to delayed and negative treatment results, suggesting that tobacco is an additional factor preventing global efforts to eliminate the TB epidemic. ${ }^{3}$ Available research also suggests that smokers are at higher risk of developing severe COVID-19 outcomes, due to the fact that tobacco increases the risk of many respiratory infections while COVID-19 also primarily attacks the lungs. 4
In many countries, including India, there is the belief that certain tobacco products like bidis are less harmful than cigarettes. However, this is not borne out by the science. ${ }^{5}$ In addition, the economic cost of diseases caused by bidi use in India is significant, amounting to INR805.5 billion per year or $0.5 \%$ of India's annual gross domestic product (GDP). ${ }^{6}$ The direct medical costs associated with bidi use exceeds $2.2 \%$ of India's total health expenditure. ${ }^{67}$

Many of these costs fall disproportionately on India's poor as they have less ability to pay for the treatment of many tobacco-related diseases like cancer and heart disease. A recent study in India found that the odds of 'catastrophic hospital expenditures' for patients with cancer was more than double the same odds for communicable diseases. ${ }^{8}$ An earlier study found that out-of-pocket expenditures due to tobacco-related medical care increased poverty rates in urban and rural areas of India by $0.08 \%$ and $0.07 \%$, respectively, meaning almost a million people impoverished each year by such expenditures.

Unfortunately, tobacco use is increasingly concentrated among poorer populations throughout the world. In India, high rates of tobacco usethose above $30 \%$ of the adult population-now occur only in lower income states like Assam and Odisha. ${ }^{10}$ Another recent study found that bidi use was highest among those of lower education, wealth and socioeconomic status. ${ }^{11}$ The lenient tax treatment of indigenous tobacco products is a key issue here, with bidis historically being taxed at relatively low levels because it has been perceived as the 'poor man's puff', without giving due consideration to the devastating impact of the 'puff' on the 'poor man's' health and productivity.

At the same time, bidi manufacturers have been sheltered from the national tax regime as a 'cottage industry'. Historically, bidi manufacturers that produce less than 2 million sticks per year have been exempt by the centre from duty, while the duty rates on bidis from larger manufacturers has been set relatively low. ${ }^{12}$ This exemption provides an opportunity for bidi manufacturers to circumvent their tax liability by establishing networks of smaller shell companies.

In 2017, India's Goods and Services Tax (GST) regimen changed the framework for indirect taxation significantly. All tobacco products were subject to the highest rate of $28 \%$ GST. However, only cigarettes and smokeless tobacco products were subject to the additional 'compensation cess' ${ }^{13}$ The 40 lakh sales turnover threshold for producers to register under the GST regimen is also more lenient than the central duty exemption since the equivalent number of bidis is greater than 2 million sticks. Hence, there is a presumption that many bidi manufacturers 
will also be GST exempt. In 2019, duty was reintroduced on all tobacco products but at a paltry rate for handmade bidis of 0.05INR/1000 in addition to the National Calamity Contingent Duty (NCCD) of INR1/1000. ${ }^{10} 14$

The aim of this paper is to assess the impact of making all bidis subject to both duty and GST. That is, removing small producer exemptions. There are several compelling reasons for doing so including to promote public health by decreasing tobacco use in all forms and thus reducing the harm from tobacco-related diseases. Additionally, the government has made up to $35 \%$ of State Disaster Relief Fund (SDRF) releases for Fiscal Year 2019-2020 available to the states for containing COVID-19. ${ }^{15}$ This is about INR49380million (roughly US\$700million) made available to the health sector through this mechanism. All tobacco products contribute to the SDRF via the NCCD. Given that tobacco is potentially a risk factor for both the spread and severity of COVID-19, it would be logical to raise duty on tobacco products to replenish the SDRF over time. ${ }^{4}$ Of course, higher tobacco taxation would also reduce tobacco use and associated harm from tobacco-related diseases including TB and COVID-19.

However, it should be recognised that bringing all bidis into India's tax regimen cannot be successfully achieved without some extra administrative costs in terms of enhanced monitoring and enforcement, with such activities needing greater coordination across different Departments and Ministries. In addition, such policies may also require high-level commitment to amending supporting legislative framework such as in relation to the law on GST.

Nonetheless, such actions would also benefit the government by increasing oversight of the tobacco supply chain-something India has committed to after becoming Party to the Protocol to Eliminate Illicit Trade in Tobacco Products (the Protocol). ${ }^{16} 17$ The informal tobacco sector poses a particular challenge to implementing the Protocol in India, and the Government may need to develop innovative measures including, for example, more comprehensive registration or licencing procedures. The recent GST reform also raises opportunities for increased efficiencies via IT platforms and the digitization of financial transactions.

We explore the impact of three related scenarios for the tax treatment of bidi in this paper. The first scenario involves the removal of duty and GST exemptions for small bidi producers as discussed. However, the tax share of bidis at $22 \%$ in this scenario would remain very low compared with $>50 \%$ cigarettes and smokeless tobacco products. Therefore, the second scenario involves removing the exemptions and also raising the duty on bidis to INR450/1000 sticks in order to increase the tax share on bidis to $50 \%$ of the retail price. In the third scenario we assess the impact of raising the duty rate on bidis to INR450/1000 sticks under the existing tax regimen, but with the small producer exemptions still applying. We include this scenario because it can be immediately implemented without legislative change. An important caveat in this third scenario is that monitoring and enforcement is sufficiently strong to prevent a large expansion of supply from the informal sector due to tax avoidance or evasion. Such considerations are explored further in the discussion.

\section{METHODS}

First, we develop a baseline profile of total bidi consumption for Fiscal Year 2018-2019. Total bidi consumption includes both 'duty-paid' and 'duty-exempt' bidi sticks, with the latter being calculated as the gap been total bidi consumption and dutypaid bidis. Total bidi consumption is calculated by multiplying

\begin{tabular}{|c|c|c|c|c|c|}
\hline & $\begin{array}{l}\text { Nominal } \\
\text { Rate* } \\
\text { (INR/1000) }\end{array}$ & $\begin{array}{l}\text { Nominal } \\
\text { Revenuet } \\
\text { (INR Mn) }\end{array}$ & $\begin{array}{l}\text { Duty Paid } \\
\text { Sticks } \\
\text { (Bn) }\end{array}$ & $\begin{array}{l}\text { Real } \\
\text { Rate } \\
\text { (INR/1000) }\end{array}$ & $\begin{array}{l}\text { Real } \\
\text { revenue } \\
\text { (INR Mn) }\end{array}$ \\
\hline 1994-1995 & 5.6 & 2200 & 393 & 23.2 & 9146 \\
\hline 1995-1996 & 5.6 & 2233 & 399 & 21.2 & 8483 \\
\hline 1996-1997 & 5.6 & 2415 & 432 & 19.9 & 8587 \\
\hline 1997-1998 & 6.6 & 2328 & 351 & 20.9 & 7317 \\
\hline 1998-1999 & 6.6 & 3233 & 487 & 19.7 & 9613 \\
\hline 1999-2000 & 6.6 & 3217 & 485 & 19.0 & 9213 \\
\hline $2000-2001$ & 8.1 & 3538 & 435 & 22.3 & 9714 \\
\hline $2001-2002$ & 9.2 & 3572 & 390 & 24.2 & 9431 \\
\hline $2002-2003$ & 9.2 & 3604 & 394 & 23.3 & 9162 \\
\hline $2003-2004$ & 9.2 & 3364 & 368 & 22.4 & 8237 \\
\hline 2004-2005 & 9.2 & 3482 & 381 & 21.5 & 8166 \\
\hline 2005-2006 & 9.2 & 3680 & 402 & 20.1 & 8089 \\
\hline 2006-2007 & 12.2 & 4262 & 351 & 25.1 & 8821 \\
\hline $2007-2008$ & 14.2 & 4840 & 341 & 26.9 & 9182 \\
\hline 2008-2009 & 14.2 & 4885 & 345 & 24.0 & 8252 \\
\hline 2009-2010 & 14.2 & 4897 & 345 & 21.7 & 7484 \\
\hline 2010-2011 & 14.2 & 4720 & 333 & 19.8 & 6588 \\
\hline 2011-2012 & 14.2 & 4590 & 324 & 18.0 & 5824 \\
\hline 2012-2013 & 16.2 & 4710 & 291 & 18.8 & 5463 \\
\hline 2013-2014 & 16.2 & 4875 & 301 & 17.7 & 5344 \\
\hline 2014-2015 & 16.2 & 4893 & 302 & 16.9 & 5113 \\
\hline $2015-2016$ & 16.2 & 4735 & 293 & 16.2 & 4735 \\
\hline
\end{tabular}

*Weighted average duty rate for handmade and machine made bidis based on handmade bidis being $98.5 \%$ of the market as per NCCD data. tMinistry of Finance, Government of India.

NCCD, National Calamity Contingent Duty.

prevalence and daily bidi consumption data from India's Global Adult Tobacco Survey (GATS) for 2016-2017..$^{1}$ Additionally, we calculate an upper and lower range of bidi consumption based on the GATS reported Sample Error for the prevalence of bidi smoking and further adjusting by $\pm 10 \%$ to account for potential misreporting of smoking intensity (ie, sticks per day).

The number of duty paid bidi sticks is taken from administrative data for NCCD collections in 2016-2017, a source which was also cross-checked against historical trends under India's old excise system prior to GST. ${ }^{12}{ }^{18}$ Specifically, the number of dutypaid bidi sticks under this old system is calculated by dividing bidi duty revenues by the weighted average rate of excise on hand and machine made bidis. ${ }^{12}$ We do not have data available on the proportion of bidi producers that are exempt from GST registration due to the 40 lakh threshold for sales turnover. However, this threshold is more lenient than the duty exemption in the pre-GST era. Therefore, we make a conservative assumption that the same proportion of bidis are both duty and GST exempt, even though potentially more are GST exempt. Such issues are reflected at least in part by our sensitivity analysis which alters the quantity of tax exempt bidis by roughly $\pm 15 \%$ compared with the GATS calculated mean.

Based on historical excise data, the number of duty-paid bidis decreased from about 400 billion sticks per annum over much the first decade shown in table 1 to about 300 billion sticks by 2015-2016. The NCCD data give the equivalent number of bidis produced to be about 275 billion sticks in 2016-2017. Table 1 also shows the bidi duty rate and associated duty revenues in real or constant 2015-2016 price terms over the past two decades. ${ }^{19}$ The real duty rate hovered above INR20/1000 for much of the first decade, then steadily decreased after peaking 
at INR27/1000 in 2007-2008. Real duty revenues also hovered around INR9 billion per annum for much of the time-frame, but decreased to less than INR5 billion per annum by 2015-2016. This decline was a combination of both lower volumes (at least of duty paid bidis) and a decreasing duty rate after accounting for inflation.

The next step is to determine the current price of duty-exempt bidis, and then the expected price increase from removing these exemptions. This is a challenge because there is limited data on the price of bidis-let alone duty-exempt bundles. However, the Labour Bureau collects price data for certain goods as part of the Consumer Price Index series, with these data indicating that the retail price of all bidis averaged about INR19.3/bundle of 25 bidis in March $2019 .{ }^{19}$ We assume the retail price of dutypaid bidis was about INR21/bundle in 2018-2019, and estimate a corresponding producer price to be INR3.0/bundle after subtracting taxes and a distribution (wholesale and retail) margin of $20 \%$ based on consultation with experts. The retail price of duty-exempt bidis was then estimated to be about INR16.4/ bundle after taking the producer price of INR13.0/bundle and adding-in GST to the distribution margin. This suggests that the retail price of duty-exempt bidis would increase by $28 \%$, from INR16.4 to INR21.0 per bundle, following the removal of small producer exemptions.

The impact of price increases on formerly duty-exempt bidis on consumption will depend primarily on the own price elasticity of demand for bidis. In India, empirical studies suggested that the elasticity of demand for bidis is around -0.92 and -0.85 in rural and urban settings, respectively. ${ }^{20}$ That is, a $10 \%$ increase in the retail price of bidis can be expected to decrease bidi consumption by about 9\%. ${ }^{19}$ Consequently, we use -0.9 as the median price elasticity of demand for bidi smokers in our analysis, within a range of -0.7 and -1.1 for sensitivity purposes.

Changes in the retail price of bidis may also have an impact the number of bidi smokers and hence, the prevalence of bidi smoking among the population. This obviously depends on the size of the price increase, as well as how responsive smokers are in terms of quitting. In this respect, the price elasticity of demand for tobacco reflects both conditional demand (ie, the intensity of smoking) and participation (ie, the act of smoking). ${ }^{21}$ Available evidence internationally shows that about half of the reduction in tobacco consumption from a given price increase is due to a reduction in conditional demand and the other half if due to a reduction in prevalence. ${ }^{21-23}$ Hence, with a price elasticity of demand of -0.9 for bidis, we might expect the price prevalence elasticity to be around -0.45 (range -0.35 to -0.55 ).

\section{FINDINGS}

Table 2 shows the estimated composition of bidi consumption for 2018-2019 based on total bidi consumption from GATS

\begin{tabular}{llll}
\hline Table 2 & Composition of bidi consumption based on gap analysis \\
\hline & $\begin{array}{l}\text { Median } \\
\text { (Bn sticks) }\end{array}$ & $\begin{array}{l}\text { Min } \\
\text { (Bn sticks) }\end{array}$ & $\begin{array}{l}\text { Max } \\
\text { (Bn sticks) }\end{array}$ \\
\hline Duty paid consumption* $^{*}$ & 275 & $(275)$ & $(275)$ \\
Total consumptiont $^{*}$ & 400 & $(336)$ & $(456)$ \\
Duty exempt consumption & 125 & $(61)$ & $(181)$ \\
\hline Market share (\%) & 31 & $(18)$ & $(40)$ \\
\hline
\end{tabular}

${ }^{*}$ NCCD data.

tGATS India 2016-17.

GATS, Global Adult Tobacco Survey; NCCD, National Calamity Contingent Duty.
Table 3 Estimated baseline composition of bidi market in 20182019

\begin{tabular}{lccc}
\hline & Duty paid & Duty exempt & All bidis \\
\hline Average producer price (INR/25) & 13.0 & 13.0 & 13.0 \\
\hline Average margin (INR/25) & 3.3 & 2.6 & 3.1 \\
\hline Average retail price (INR/25) & 21.0 & 16.4 & 19.5 \\
\hline Average duty (INR/25)* & 0.0 & 0.0 & 0.0 \\
\hline Average GST (INR/25)† & 4.6 & 0.7 & 3.3 \\
\hline Average tax (INR/25) & 4.6 & 0.7 & 3.3 \\
Consumption (billion sticks) & 275 & 125 & 400 \\
Smokers (million adults) & 49 & 22 & 71 \\
Smoking rate (\% adults) & 5.3 & 2.4 & 7.7 \\
\hline Duty revenue (INR billion) & 0.3 & 0.0 & 0.3 \\
GST revenue (INR billion) & 50.5 & 3.6 & 54.2 \\
\hline Total tax revenue (INR billion) & 50.8 & 3.6 & 54.5 \\
\hline
\end{tabular}

*Duty $=1.05$ per 1000 sticks.

tGST on the retailer's margin for duty exempt bidis.

GST, Goods and Services Tax.

2016-2017 of around 400 (336-456) billion sticks per annum and an average of 275 billion duty-paid bidi sticks per annum. Thus, the number of duty-exempt bidis is estimated at 125 (61-181) billion sticks per annum, representing 31\% (18\%$40 \%)$ of the total bidi market.

Table 3 shows the baseline situation for India's bidi market in 2018-2019, with 275 billion duty-paid sticks and 125 billion duty-exempt sticks (ie, median as above). The retail price of duty-paid bidis is around INR21/bundle, while the retail price for exempt bidis is around INR16/bundle. Duty paid-bidi sticks are subject to tax of INR4.6/pack representing $22 \%$ of the retail price. This finding is consistent with similar studies covering the post-GST period. ${ }^{13}$ On the other hand, only the distribution margin is subject to GST for duty-exempt bidis and therefore these bidis are subject to tax of just INR0.7/pack representing $4 \%$ of the retail price. On average, across the whole bidi market, tax is estimated to account for about $17 \%$ of the retail price.

As discussed, duty-exempt bidis are estimated to account for around $31 \%(18 \%-40 \%)$ of all bidi consumption. We can calculate the equivalent number of duty-exempt smokers based on the assumption that all bidi smokers are equally intensive (ie, they consume a similar number of sticks per day). Consequently, India has around 71 million bidi smokers as per GATS 2016-2017, including about 22 (12-30) million smokers of duty-exempt bidis (table 3$)$. The latter represents about 2.4\% (1.3\%-3.2\%) of India's adult population. Total tax revenue from bidi sticks in 2018-2019 is estimated at INR54.5 (53-56) billion per annum, with this amount mostly from GST.

Table 4 shows the projected impact of removing the duty and GST exemptions for small bidi producers. The price of 'currently exempt' bidis increases by INR4.6/pack or $28 \%$ as is necessary to reflect the imposition of duty and GST. However, the market average retail price of bidis increases by just $8 \%$ reflecting that around $70 \%$ of bidi consumption is already subject to these taxes.

Total bidi consumption is projected to decrease by $6 \%$ (3\%-10\%) reflecting $25(10-43)$ billion fewer bidi sticks consumed annually. The number of bidi smokers would decrease by 2.2 (1-0-3.6) million adults, reflecting a 3.1\% (1.4\%-4.8\%) relative reduction in the rate of bidis smoking from $7.7 \%$ to $7.5 \%$ of all adults in India.

Annual tax revenues from bidi consumption-mostly generated from GST at this point-would increase by INR14.8 


\begin{tabular}{|c|c|c|c|}
\hline & Duty paid & Currently exempt & All bidis \\
\hline \multicolumn{4}{|c|}{ Average retail price (INR/25) } \\
\hline 2018-2019 & 21.0 & 16.4 & 19.5 \\
\hline Projected & 21.0 & 21.0 & 21.0 \\
\hline Change & 0.0 & 4.6 & 1.5 \\
\hline$\%$ change & 0 & 28 & 8 \\
\hline \multicolumn{4}{|c|}{ Consumption (billion sticks) } \\
\hline 2018-2019 & 275 & 125 & 400 \\
\hline Projected & 275 & 100 & 375 \\
\hline Change & 0.0 & -25.0 & -25.0 \\
\hline$\%$ change & 0 & -20 & -6 \\
\hline \multicolumn{4}{|c|}{ Smokers (million adults) } \\
\hline 2018-2019 & 49 & 22 & 71 \\
\hline Projected & 49 & 20 & 69 \\
\hline Change & 0.0 & -2.2 & -2.2 \\
\hline$\%$ change & 0 & -10 & -3 \\
\hline \multicolumn{4}{|c|}{ Duty revenue (INR billion) } \\
\hline 2018-19 & 0.3 & 0.0 & 0.3 \\
\hline Projected & 0.3 & 0.1 & 0.4 \\
\hline Change & 0.0 & 0.1 & 0.1 \\
\hline \multicolumn{4}{|c|}{ GST revenue (INR billion) } \\
\hline 2018-2019 & 50.5 & 3.6 & 54.2 \\
\hline Projected & 50.5 & 18.3 & 68.9 \\
\hline Change & 0.0 & 14.7 & 14.7 \\
\hline \multicolumn{4}{|c|}{ Total tax revenue (INR billion) } \\
\hline 2018-2019 & 50.8 & 3.6 & 54.5 \\
\hline Projected & 50.8 & 18.5 & 69.3 \\
\hline Change & 0.0 & 14.8 & 14.8 \\
\hline
\end{tabular}

GST, Goods and Services Tax.

$(6.8-22.8)$ billion or by $27 \%(13 \%-41 \%)$ on the baseline. Removing the exemptions for small bidi producers in India would, therefore, represent a 'win-win' scenario for both public health and revenue collection, while also helping to bring the tobacco supply-chain under greater government oversight and control.

Removing the small producer's exemptions for bidis would be a major reform to India's system of tobacco taxation. However, there would still be significant scope for more progress becauseat just $22 \%$-the tax burden on bidis is still very low compared with $>50 \%$ in the case of both cigarettes and smokeless tobacco products. Table 5 presents the projected impact of raising duty on all bidis in order to achieve a tax burden of $50 \%$, making bidis comparable to other tobacco products. This would require duty to increase to about INR450/1000 sticks.

The average retail price of all bidis would increase by INR19.5/ pack or by $100 \%$. Note such an increase is absolutely necessary to due to the fact that bidis have remained very affordable over the past decade due, in part, to lenient tax treatment by both the centre and the GST Council post-GST implementation. ${ }^{10}$

Total bidi consumption under this scenario is projected to decrease by 46\% (37\%-55\%) reflecting around 184 (123-249) billion fewer bidi sticks consumed each year. The number of bidi smokers would decrease significantly by 16.5 (12.4-20.5) million adults, reflecting a $23 \%(18 \%-27 \%)$ relative reduction in the prevalence rate of bidis smoking from $7.7 \%$ to $5.9 \%$ of all adults in India.

In addition, tax revenues from bidis would increase by INR116 (75-165) billion per annum. This would include an extra INR96.7billion in central duty revenue and an extra
Table 5 Impact of removing exemptions and applying duty of INR450/1000

\begin{tabular}{|c|c|c|c|}
\hline & Duty paid & Currently exempt & All bidis \\
\hline \multicolumn{4}{|c|}{ Average retail price (INR/25) } \\
\hline 2018-2019 & 21.0 & 16.4 & 19.5 \\
\hline Projected & 39.0 & 39.0 & 39.0 \\
\hline Change & 18.0 & 22.7 & 19.5 \\
\hline$\%$ change & 86 & 138 & 100 \\
\hline \multicolumn{4}{|c|}{ Consumption (billion sticks) } \\
\hline 2018-2019 & 275 & 125 & 400 \\
\hline Projected & 158 & 58 & 216 \\
\hline Change & -117.1 & -67.2 & -184.3 \\
\hline$\%$ change & -43 & -54 & -46 \\
\hline \multicolumn{4}{|c|}{ Smokers (million adults) } \\
\hline 2018-19 & 49 & 22 & 71 \\
\hline Projected & 39 & 16 & 55 \\
\hline Change & -10.5 & -6.0 & -16.5 \\
\hline$\%$ change & -21 & -27 & -23 \\
\hline \multicolumn{4}{|c|}{ Duty revenue (INR billion) } \\
\hline 2018-2019 & 0.3 & 0.0 & 0.3 \\
\hline Projected & 71.1 & 26.0 & 97.0 \\
\hline Change & 70.8 & 26.0 & 96.7 \\
\hline \multicolumn{4}{|c|}{ GST revenue (INR billion) } \\
\hline 2018-2019 & 50.5 & 3.6 & 54.2 \\
\hline Projected & 53.9 & 19.7 & 73.7 \\
\hline Change & 3.4 & 16.1 & 19.5 \\
\hline \multicolumn{4}{|c|}{ Total tax revenue (INR billion) } \\
\hline 2018-2019 & 50.8 & 3.6 & 54.5 \\
\hline Projected & 125.0 & 45.7 & 170.7 \\
\hline Change & 74.2 & 42.0 & 116.2 \\
\hline
\end{tabular}

GST, Goods and Services Tax.

INR19.5 billion in GST for the state governments. The former could potentially be used to help replenish the SDRF via an increase in the NCCD component of central duty.

Lastly, table 6 shows the impact of raising duty on bidis to INR450/sticks under the existing tax regime in which the small producer exemptions still apply. An important caveat here is that monitoring and enforcement is sufficiently robust to prevent a large expansion of supply from the informal sector due to tax avoidance or evasion practices of manufacturers. This risk is explored in more detail during the discussion. Under this scenario, bidi consumption would decrease by $29 \%(21 \%-$ 41\%) representing around 117 (96-137) billion fewer bidis sticks consumed in India. Total tax revenues would increase by INR74.2 (59-91) billion, including about INR71 billion extra in duty revenue and INR3 billion in extra GST revenue.

\section{DISCUSSION}

Our analysis confirms that bringing all bidis into India's tax regime would generate significant benefits in terms of public health-as would increasing the duty rate on this product. Such measures also make good sense from a tax policy design perspective since cigarettes and smokeless products are taxed significantly higher. While consumers perceive bidis to be 'inferior' goods relative to cigarettes in India, there is still a risk that widening that tax differential between them can encourage some cigarette smokers to trade-down to bidis rather than to quit smoking. Similarly, there is a high proportion of dual userswith around $20 \%$ of all smokers using both bidis and cigarettes. ${ }^{1}$ 
Table 6 Impact of maintaining exemptions and applying duty of INR450/1000

\begin{tabular}{|c|c|c|c|}
\hline & Duty paid & Currently exempt & All bidis \\
\hline \multicolumn{4}{|c|}{ Average retail price (INR/25) } \\
\hline 2018-2019 & 21.0 & 16.4 & 19.5 \\
\hline Projected & 39.0 & 16.4 & 29.0 \\
\hline Change & 18.0 & 0.0 & 9.5 \\
\hline$\%$ change & 86 & 0 & 49 \\
\hline \multicolumn{4}{|c|}{ Consumption (billion sticks) } \\
\hline 2018-2019 & 275 & 125 & 400 \\
\hline Projected & 158 & 125 & 283 \\
\hline Change & -117.1 & 0.0 & -117.1 \\
\hline$\%$ change & -43 & 0 & -29 \\
\hline \multicolumn{4}{|c|}{ Smokers (million adults) } \\
\hline 2018-2019 & 49 & 22 & 71 \\
\hline Projected & 39 & 22 & 61 \\
\hline Change & -10.5 & 0.0 & -10.5 \\
\hline$\%$ change & -21 & 0 & -15 \\
\hline \multicolumn{4}{|c|}{ Duty revenue (INR billion) } \\
\hline 2018-2019 & 0.3 & 0.0 & 0.3 \\
\hline Projected & 71.1 & 26.0 & 97.0 \\
\hline Change & 70.8 & 26.0 & 96.7 \\
\hline \multicolumn{4}{|c|}{ GST revenue (INR billion) } \\
\hline 2018-2019 & 50.5 & 3.6 & 54.2 \\
\hline Projected & 53.9 & 3.6 & 57.6 \\
\hline Change & 3.4 & 0.0 & 3.4 \\
\hline \multicolumn{4}{|c|}{ Total tax revenue (INR billion) } \\
\hline 2018-2019 & 50.8 & 3.6 & 54.5 \\
\hline Projected & 125.0 & 3.6 & 128.7 \\
\hline Change & 74.2 & 0.0 & 74.2 \\
\hline
\end{tabular}

Consequently, empirical studies tend to find that bidis are complementary products, rather than close substitutes, to other forms of tobacco like cigarettes and leaf tobacco. ${ }^{2024}$

Our analysis also highlights the untapped revenue potential for India's central and state governments via duty and GST on bidis. Higher duty rates on all tobacco products can help to replenish the SDRF, while also reducing tobacco use and associated health risks. At the same time, it should be recognised that bringing the informal tobacco sector into the tax regimen would not be without extra administrative costs. Such activities are also likely to need greater coordination across stakeholder ministries such as finance, labour, agriculture and health. It may also require high-level commitment to amend associated legislation and to overcome strong industry interference.

Nonetheless, such actions would also increase the government's oversight of the tobacco supply chain-something India has committed to by becoming Party to the Protocol to Eliminate Illicit Trade in Tobacco Products (the Protocol). The size of India's informal bidi and smokeless tobacco sector poses a particular challenge for implementation of the Protocol, and India may need to develop innovative measures to address this issue. The recent GST reform process, for example, presents an opportunity for increased monitoring of the tobacco sector via IT platforms and the digitalisation of financial transactions, while also helping to modernise India's overall system of taxation.

We acknowledge that India faces a number of barriers to comprehensive reform in the bidi sector. Thus, we have included a third scenario in which the duty rate on bidis is increased, without any changes to the tax regime or supporting legislation.
The impact of this scenario, however, partly depends on a caveat that the supply of duty-exempt bidis does not expand significantly. A similar situation has occurred in the past in other countries, for example, with kreteks in Indonesia until the Government passed legislation banning the establishment of new small-to-mid scale kretek producers. ${ }^{2425}$

However, it is not clear what scope duty-exempt small bidi producers in India have to legally increase their production capacity given the exemption thresholds. Similarly, a lack of industry monitoring hinders our ability to understand historical trends in this matter, including potentially due to tax avoidance. In any case, this question points towards the same conclusion that India needs to strengthen its oversight and control of the tobacco supply chain, particularly with respect to the informal sector. The strengthening of tax administration in this area should be seen as part of a comprehensive tobacco control strategy, including in combination with higher tobacco taxes to

\section{What this paper adds}

\section{What is already known on this subject}

- Majority of India's smokers consume bidis rather than cigarettes, with the Global Adult Tobacco Survey for 2016-2017 reporting 72 million bidi smokers representing $7.7 \%$ of India's adult population. As an indigenous product, bidis have historically been treated very leniently in terms of taxation. It has been sheltered as a 'cottage industry', with bidi manufacturers producing less than 2 million sticks per year being exempt from central duty. This has continued under the Goods and Services Tax (GST) regimen and many small bidi manufacturers will have escaped the GST net due to the 40 lakh sales turnover threshold for GST registration. Consequently, a large proportion of the bidi market is effectively untaxed, which makes tax policy less effective as a tool for both tobacco control and revenue generation.

What important gaps in knowledge exist on this topic

- There is very little known about the absolute quantity or market share of tax-exempt bidis, except that it is likely sizeable. The tax exemptions also create a problem for tax policy design and implementation because the tax base (ie, consumption) is less certain, because consumers can switch to tax-exempt brands and bidi manufacturers can manipulate the policies under which exemptions apply. Such issues are technical problem in addition to the political economy of bidi taxation in India.

\section{What this paper adds}

- The aim of this paper is to assess the impact of making all bidis subject to both excise duty and GST. That is, removing small producer exemptions for bidi manufacturers. There are strong reasons for doing so including to promote public health by decreasing tobacco use in all its forms, and to generate tax revenue from a largely untapped source in terms of the tobacco tax base. In addition, such actions would increase the Government's oversight of the tobacco supply chain-something it has committed to by becoming Party to the Protocol to Eliminate Illicit Trade in Tobacco Products. We find that tax-exempt bidis account for about $31 \%$ of the total bidi market. Removing the small producer tax exemptions would decrease total bidi consumption by $6 \%$ and the number of bidi smokers by 2.2 million adults, while also generating INR14.8 billion in tax revenues. 
ultimately achieve WHOs recommendation tax should account for at least $75 \%$ of the price of all tobacco products.

Contributors MG designed the study, collected the data, undertook the analysis, and drafted the manuscript. VM and PS contributed to country data collection, analysis, and drafting of the manuscript. FT and JP contributed to the study design and drafting of the manuscript.

Funding The authors have not declared a specific grant for this research from any funding agency in the public, commercial or not-for-profit sectors.

Competing interests None declared.

Patient consent for publication Not required.

Provenance and peer review Not commissioned; externally peer reviewed.

Data availability statement All data relevant to the study are included in the article or uploaded as online supplemental information.

Open access This is an open access article distributed in accordance with the Creative Commons Attribution Non Commercial (CC BY-NC 4.0) license, which permits others to distribute, remix, adapt, build upon this work non-commercially, and license their derivative works on different terms, provided the original work is properly cited, appropriate credit is given, any changes made indicated, and the use is non-commercial. See: http://creativecommons.org/licenses/by-nc/4.0/.

\section{ORCID iD}

Mark Goodchild http://orcid.org/0000-0002-1826-1343

\section{REFERENCES}

1 WHO. Global adult tobacco survey GATS 2 India 2016-17. Mumbai and New Delhi: Tata Institute of Social Sciences and Ministry of Health and Family Welfare, Government of India, 2018.

2 World Health Organization. WHO report on the global tobacco epidemic, 2017: monitoring tobacco use and prevention policies. Geneva: World Health Organization, 2017.

3 Wang EY, Arrazola RA, Mathema B, et al. The impact of smoking on tuberculosis treatment outcomes: a meta-analysis. Int J Tuberc Lung Dis 2020;24:170-5.

4 WHO. Q\&A on COVID-19 and smoking. Geneva: World Health Organization, 2020. https://www.who.int/news-room/q-a-detail/q-a-on-smoking-and-covid-19

5 MHFW. Bidi smoking and public health. Delhi, Ministry of health and family welfare. Government of India, 2008.

6 John RM, Sung H-Y, Max W. Economic cost of tobacco use in India, 2004. Tob Control 2009;18:138-43.
7 John RM. Economic costs of diseases and deaths attributable to bidi smoking in India, 2017. Tob Control 2019;28:513-8.

8 Rajpal S, Kumar A, Joe W. Economic burden of cancer in India: evidence from cross-sectional nationally representative household survey, 2014. PLoS One 2018;13:e0193320.

9 John RM, Sung H-Y, Max WB, et al. Counting 15 million more poor in India, thanks to tobacco. Tob Control 2011;20:349-52.

10 Goodchild M, Sinha P, Gill Munish V, et al. Changes in the affordability of tobacco products in India during 2007/2008 to 2017/2018: a price-relative-to-income analysis. WHO South East Asia J Public Health 2020;9:73-81.

11 Mbulo L, Palipudi KM, Smith T, et al. Patterns and related factors of bidi smoking in India. Tob Prev Cessat 2020;6:28.

12 Sunley E. India: the Tax treatment of bidis. Paris: International Union Against Tuberculosis and Lung Disease, 2008.

13 John RM, Dauchy E, Goodchild M. Estimated impact of the GST on tobacco products in India. Tob Control 2019;28:506-12.

14 Budget speech. Available: https://www.indiabudget.gov.in/doc/Budget_Speech.pdf

15 SDRF/NDRF. Available: https://www.ndmindia.nic.in/response-fund

16 World Health Organization. WHO framework convention on tobacco control. Geneva: World Health Organization, 2003.

17 World Health Organization. Protocol to eliminate illicit trade in tobacco products. Geneva: World Health Organization, 2013.

18 Ministry of finance. Available: https://www.finmin.nic.in/

19 Government of India. Consumer price index for industrial workers. New Delhi: Labour Bureau, Ministry of Labour and Employment, Government of India, 2020.

20 John RM. Price elasticity estimates for tobacco products in India. Health Policy Plan 2008;23:200-9.

21 National Cancer Institute. The economics of tobacco and tobacco control. National cancer Institute tobacco control monograph 21. NIH publication No. 16-CA-8029A. Bethesda, MD: U.S. Department of Health and Human Services, National Institutes of Health, National Cancer Institute, 2016.

22 IARC. Effectiveness of Tax and price policies for tobacco control. IARC handbooks of cancer prevention: tobacco control. 14. Lyon: International Agency for Research on Cancer, 2011.

23 van Walbeek C. A simulation model to predict the fiscal and public health impact of a change in cigarette excise taxes. Tob Control 2010;19:31-6.

24 Jawad M, Lee JT, Glantz S, et al. Price elasticity of demand of non-cigarette tobacco products: a systematic review and meta-analysis. Tob Control 2018;27:689-95.

25 World Health Organization. Who technical manual on tobacco Tax administration. Geneva: World Health Organization, 2011. https://www.who.int/tobacco/publications/ tax_administration/en/ 